\title{
Self-Stigma in Relatives of people with Mental Illness scale: development and validation
}

\author{
E. Morris, C. Hippman, G. Murray, E.E. Michalak, J.E. Boyd, J. Livingston, A. Inglis, P. Carrion and J. Austin
}

\section{Background}

Serious mental illness (SMI) is profoundly stigmatised, such that there is even an impact on relatives of people with SMI.

\author{
Aims \\ To develop and validate a scale to comprehensively measure \\ self-stigma among first-degree relatives of individuals with SMI.
}

\section{Method}

We conducted group interviews focusing on self-stigma with first-degree relatives $(n=20)$ of people with SMl, from which 74 representative quotations were reframed as Likert-type items. Cognitive interviews with relatives $(n=11)$ identified 30 items for the Self-Stigma in Relatives of people with Mental IIIness (SSRMI) scale. Relatives $(n=195)$ completed the scale twice, a month apart, together with four external correlate scales.

\section{Results}

The 30-item SSRMI was reliable, with scores stable over time. Its single-factor structure allowed generation of a 10-item version. Construct validity of 30 - and 10-item versions was supported by expected relationships with external correlates.

\section{Conclusions}

Both versions of the SSRMI scale are valid and reliable instruments appropriate for use in clinical and research contexts.

\section{Declaration of interest}

None.

\section{Copyright and usage}

(c) The Royal College of Psychiatrists 2018.
Mental illnesses are highly stigmatised conditions. For those with mental illnesses such as schizophrenia, symptoms have a dramatic impact on language, thought, affect, perception and sense of self. ${ }^{1}$ Even so, for some, the burden of stigma actually outweighs that of the illness. ${ }^{2}$ Not only do individuals with mental illness experience stigma, but their family members report feeling stigmatised too. ${ }^{3-5}$ Stigma is a complex, multifaceted process that operates at several levels, including: institutions and structures, ${ }^{6}$ society (or the public) ${ }^{7}$ and at the level of the individual. Self-stigma, also known as internalised stigma, operates at the level of the individual, and can be conceptualised as 'a process whereby affected individuals endorse stereotypes [...], anticipate social rejection, consider stereotypes to be self-relevant, and believe they are devalued members of society. ${ }^{8}$ Self-stigma has been conceptualised as a counterpoint to constructs such as empowerment ${ }^{9}$ and self-efficacy. ${ }^{8}$ Self-stigma grows from experiences and perceptions of discrimination, ${ }^{8}$ and has been postulated to be central to the psychological harm caused by stigma. ${ }^{8,10,11}$ Studies show that stigma is experienced, ${ }^{12}$ perceived $^{13}$ and internalised by family members of people with mental illness. This phenomenon has been dubbed 'courtesy stigma ${ }^{3}$ or 'stigma by association'. Research suggests that selfstigma is as damaging for relatives as it is for people with mental illness themselves, ${ }^{14}$ causing psychological distress, suicidal thoughts ${ }^{14}$ and decreased quality of life; ${ }^{15}$ however, it is postulated to be amenable to change. ${ }^{9}$ In order to evaluate the effectiveness of any interventions designed to mitigate self-stigma among relatives of people with mental illness, robust instruments with which to measure it are required.

Whereas the Internalised Stigma Mental Illness scale (ISMI) was developed and validated to measure self/internalised stigma in people with lived experience of mental illness, ${ }^{16}$ no scales have been purpose-built to specifically and comprehensively measure self/internalised stigma among first-degree family members of individuals with mental illness. For example, of the scales that exist for measuring stigma among family members, two ${ }^{17,18}$ were designed for relatives who are providing care for their affected family member (and are therefore not applicable to relatives who are not directly involved with caregiving). Further, one of these instruments includes only a five-item stigma subscale, ${ }^{18}$ and the other ${ }^{17}$ omits a core content area (culpability) that is conceptually important in self/ internalised stigma. ${ }^{19}$ An adaptation of the ISMI has been developed for use with parents of individuals with mental illness, ${ }^{20}$ and although this has good psychometric properties, it was not developed and purpose-designed for family members, and addresses only one kind of relative - parents. Last, the Devaluation of Consumers and Consumer Families (DCCF) scale has also been used, but this was originally developed to measure family members' perceived social stigma/social stereotype endorsement rather than focusing specifically on self/internalised stigma. ${ }^{21}$ Importantly, it appears that the existing scales that have been used to assess self/internalised stigma among relatives have been founded on the implicit assumption that it is associated with social proximity/caregiving, ${ }^{16,18}$ whereas clinical experience and research suggests an important role for biological relatedness in self/internalised stigma. ${ }^{5}$ Tools with which to measure self-stigma in family members of people with mental illness are needed to allow the rigorous assessment of the effectiveness of interventions that may be applied to tackle it. Thus, we aimed to develop and validate a psychometric instrument with which to specifically and comprehensively measure self-stigma among relatives of people with serious mental illness (SMI, specifically, schizophrenia, schizoaffective disorder or bipolar disorder), founding our work on the idea that biological relatedness is important in self-stigma. ${ }^{5}$

\section{Method}

\section{Scale development overview}

We adopted a structured process that involved both inductive and deductive components that unfolded over several phases. In phase I, we used an inductive group interview-based approach with first-degree family members (biological parents, siblings and children) of people with mental illness to generate a broad array of potential scale items. In phase II we deductively appraised potential scale items in light of the theoretical construction of stigma, to select items for a first draft of a scale. In phase III, we used feedback gathered from cognitive interviews with first-degree relatives of people with mental illness to reduce the number of scale items. Finally, 
in phase IV, the resulting 30-item scale was validated in a cohort of 195 first-degree relatives of individuals with mental illness.

In all phases, participants were first-degree relatives of people with schizophrenia, schizoaffective disorder or bipolar disorder whom we purposively sampled from family support groups, advocacy agencies and email lists. We confirmed participants' relatives' psychiatric diagnoses using the Family Interview for Genetic Studies, ${ }^{22}$ administered via telephone (Table 1). For ecological validity, participants were not excluded if they had a personal history of mental illness, but were asked to consider the influence of a single, specific index family member's diagnosis for activities involved in study participation. The entire study was carried out in accordance with the declaration of Helsinki, and approved by the research ethics board at the University of British Columbia. All participants provided informed consent.

\section{Phase I: item generation (group interviews)}

We conducted six group interviews with participants, including three for relatives of people with schizophrenia/schizoaffective disorder (one each for parents, siblings and adult children), and three for relatives of people with bipolar disorder (again, one each for parents, siblings and adult children) (Table 1). Group interviews (each $\sim 2 \mathrm{~h}$ in length) were semi-structured in format, with discussion focused on stigma and feelings of self-stigma because of having a family member with a mental illness (See supplementary Appendix 1 for the interview guide; available at https://doi.org/ 10.1192/bjp.2017.23).

The interviews were audio-recorded, transcribed verbatim and checked for accuracy. Two team members carefully and independently reviewed each transcript to identify quotations that seemed representative of, or particularly meaningful to, the group in which they occurred. An inclusive, consensus-based approach used by the reviewers led to the identification of 130 quotations to be considered for use as potential scale items.

\section{Phase II: item selection (expert input, deductive phase)}

Six members of the team reviewed each of the 130 quotations identified as potential scale items. Each quotation was categorised by group consensus to one of the five core theoretical content areas of self-stigma identified from the literature ${ }^{19}$ (see Table 2). We reached consensus that no additional core content areas were present in the interviews, and that no important topics were missing, and guided by the existing literature, operationalised our concept of self-stigma in relatives of individuals with mental illness and its core components (Table 2). To produce a first draft of a scale, we selected 74 quotations that collectively covered all five core content areas of self-stigma, and ensured that all interview groups were represented. Then, we carefully reframed the 74 quotations such that they could be answered using a Likert scale response (using the following anchors: 1, strongly disagree; 2, disagree; 3 , neither agree nor disagree; 4 , agree, 5 , strongly agree), and modified the wording of items to clarify meaning, and to ensure that some items would be reverse coded, thus generating our first draft of the scale.

\section{Phase III: item reduction (cognitive interviews)}

We conducted cognitive interviews with 11 first-degree relatives of people with SMI (Table 1) during which participants talked through their process of answering each of the $74 \mathrm{draft}$ scale items and provided feedback on their understandability and pertinence. Interviews were audio-recorded and participants' comments on each item were transcribed. Again, six team members collaboratively reviewed the data from the cognitive interviews and removed or revised those items identified by interviewees as lower priority, problematic or redundant, while ensuring that all of the five core conceptual domains of stigma were still well represented. Through this process, the 74 items were reduced to a scale composed of 30 items that was piloted in the validation phase of the study (see supplementary Appendix 2).

\section{Phase IV: validation}

Overview

Since full psychometric validation of scales requires five to ten participants per item, ${ }^{23}$ and the draft SSRMI had 30 items, we aimed to recruit approximately 200 participants. Participants were asked to complete a demographic information questionnaire as well as the 30-item SSRMI scale (for scoring and participant instructions, see supplementary Appendix 2), along with four other validated

\begin{tabular}{|c|c|c|c|}
\hline Characteristics & Phase I $(n=20)$ & Phase III $(n=11)$ & Phase IV $(n=195)$ \\
\hline Age, mean (s.d.) & $51.0(14.6)$ & $47.6(10.7)$ & $50.8(13.5)$ \\
\hline \multicolumn{4}{|l|}{ Sex, $n(\%)$} \\
\hline Male & $6(30.0)$ & $5(45.5)$ & $28(14.4)$ \\
\hline Female & $14(70.0)$ & $6(54.5)$ & $166(85.1)$ \\
\hline Unknown & & & $1(0.5)$ \\
\hline Primary caregiver, $n(\%)$ & $9(45.0)$ & $4(36.4)$ & $40(20.5)^{a}$ \\
\hline $\begin{array}{l}\text { Personal experience with mental illness, }{ }^{b} n(\%) \\
\text { Index relative with mental illness, } n(\%)\end{array}$ & $6(30.0)$ & $3(27.3)$ & 22 (11.3) \\
\hline Parent & $5(25.0)$ & $3(27.3)$ & $50(25.6)$ \\
\hline Child & $9(45.0)$ & $4(36.4)$ & 79 (40.5) \\
\hline Sibling & $6(30.0)$ & $4(36.4)$ & $66(33.8)$ \\
\hline \multicolumn{4}{|l|}{ Psychiatric diagnosis of index relative, ${ }^{\mathrm{C}} \mathrm{n}(\%)$} \\
\hline Schizophrenia & $6(30.0)$ & $4(36.4)$ & $55(28.2)$ \\
\hline Schizoaffective disorder & $6(30.0)$ & $2(18.2)$ & $36(18.5)$ \\
\hline Bipolar disorder & $8(40.0)$ & $5(45.5)$ & $104(53.3)$ \\
\hline Years since onset of psychiatric illness in index relative, mean (s.d.) & $18.1(13.3)$ & $18.2(16.0)$ & $15.2(15.1)$ \\
\hline Total number of relatives with mental illness, ${ }^{d}$ mean (s.d.) & $1.7(1.1)$ & $1.7(0.8)$ & $2.8(1.0)$ \\
\hline
\end{tabular}


Overarching concept: self-stigma in first-degree relatives of people with serious mental illness

Operational definition: a process of stereotyping, separation, devaluation, culpability, status loss and discrimination ${ }^{19}$ that is expected, experienced or shared by a family member due to their biological relatedness ${ }^{5}$ and/or their role as a first-degree relative of someone with serious mental illness. ${ }^{19}$

$\begin{aligned} & \text { Core component of overarching } \\ & \text { concept }\end{aligned}$
$\begin{aligned} & \text { Stereotyping } \\ & \text { Separation }\end{aligned}$
$\begin{array}{r}\text { Family mectively held undesirable characteristics, which are assumed to be shared by people in a stigmatised group, and are } \\ \text { endorsed and internalised by family members. }\end{array}$
$\begin{aligned} & \text { exclusion, isolation, withdrawal). } \\ & \text { Emotional reactions and responses to feeling less valuable, or that one's worth has been depreciated (for example feelings } \\ & \text { of shame, embarrassment, anger, anxiety, pity, fear). } \\ & \text { Fulpability } \\ & \text { Feelings of being responsible for their family member's serious mental illness (for example blame, guilt). } \\ & \text { Family members' feelings of having been moved in a downward direction on the status hierarchy, leading to forms of } \\ & \text { inequality. }\end{aligned}$

questionnaires to assess construct validity. This set of scales was administered to participants twice to establish test-retest reliability: at baseline $\left(T_{1}\right)$ and 1 month later $\left(T_{2}\right)$.

\section{Psychometric analysis}

Data from the validation phase (phase IV) were screened for missing values. Randomly missing values were replaced at the item level using maximum likelihood interpolation for SSRMI at $T_{1}$ and $T_{2}$. The data were then screened for multivariate outliers.

Tests for normal distribution including Bartlett's test of sphericity and the Kaiser-Meyer-Olkin measure of sampling adequacy were also performed. For establishing internal consistency, Cronbach's alphas for the SSRMI as a whole, and for each of the five individual core conceptual content areas were calculated. Test-retest reliability was calculated for the SSRMI scale as a whole and for each of the content areas.

\section{Exploratory-factor analysis}

The $T_{1}$ data were used to explore the factor structure of the SSRMI. Factor analyses were completed with scree plot tests, the Kaiser criterion, parallel analysis and Velicer's minimum average partial (MAP) test. Because the nominal structure of the instrument involved five core conceptual content areas, a maximum likelihood extraction set to extract five factors with an oblique rotation (direct oblimin) was then performed. Subsequent tests involving two, three and four factors were also conducted. A final exploratory-factor analysis was conducted to investigate a one-factor structure for the items, based on the results from the scree plot test (see supplementary Fig. 1).

\section{Construct validation}

The selection of our external correlates was informed by the psychometric validation of the ISMI. ${ }^{16}$ We selected: the Centre for Epidemiological Studies Depression Scale (CES-D) to measure depressive symptoms, ${ }^{24}$ the $\mathrm{DCCF}^{21}$ to measure perceived stigma, the Rosenberg Self Esteem Scale (RSE) $)^{25}$ to measure self-esteem, and a subset of participants also completed a measure of empowerment (Empowerment Scale (ES)). ${ }^{26}$ We expected the CES-D and DCCF scores to have moderate positive correlations with SSRMI, and the RSE and ES to have moderate negative correlations with SSRMI. Correlations between the SSRMI and the CES-D, RSE, DCCF and ES were calculated.

\section{Developing the ten-item SSRMI}

Given that exploratory-factor analysis suggested a single-factor latent structure for the instrument, we also developed a ten-item version of the SSRMI. To ensure breadth of content was retained, we identified two items from each of the five conceptual content areas that best captured the core of each domain, according to group consensus. Each selected item had a significant loading on the single-factor solution to the original 30-item exploratoryfactor analysis. Psychometrics analyses were conducted for the ten-item version.

\section{Results}

The results of the phase IV validation are presented here. Participant characteristics are described in Table 1. For the 30item SSRMI, $26 \%$ of participants had scores at the midpoint or higher at $T_{1}$.

\section{Data preparation}

A total of $n=195$ participants participated in the validation phase. Two participants' data exceeded the critical value for multivariate outliers and were excluded from the factor analyses, leaving $n=193$ for factor analysis. A total of 24 participants did not respond to any SSRMI items at $T_{2}$ and were included in analyses involving only $T_{1}$ data, but excluded from analyses requiring $T_{1}$ data. We used a multiple imputation procedure $\mathrm{e}^{27}$ to replace random missing values (107 at $T_{1}$, and 20 at $T_{2}$ ).

\section{Thirty-item scale}

Data from the SSRMI were approximately normally distributed. Significant intercorrelations were found between the variables according to Bartlett's test of sphericity $\left(\chi^{2}(435)=2573.96, P<\right.$ 0.001 ) and the Kaiser-Meyer-Olkin measure of sampling adequacy (0.87).

\section{Internal reliability}

Cronbach's alpha for the 30-item scale was excellent $(\alpha=0.90)$. Reliability of the stereotyping ( $\alpha=0.62)$, and status loss and discrimination $(\alpha=0.41)$ core conceptual content areas were inadequate against the accepted criterion for Cronbach's alpha of 0.70 . Reliability of the separation content area $(\alpha=0.76)$, culpability content area $(\alpha=0.77)$ and devaluation content area were adequate $(\alpha=0.77)$. 
Table 3 Mean Self-Stigma in Relatives of people with Mental IIIness scores for the 30 -item and 10 -item scales

\begin{tabular}{|c|c|c|c|c|}
\hline & $\begin{array}{l}\text { 30-item scale, } \\
\text { mean score (s.d.) }\end{array}$ & $P$ & $\begin{array}{l}\text { 10-item scale, } \\
\text { mean score (s.d.) }\end{array}$ & $P$ \\
\hline \multicolumn{5}{|l|}{ Sex } \\
\hline Male & $2.62(0.76)$ & 0.35 & $2.54(0.93)$ & 0.27 \\
\hline Female & $2.51(0.60)$ & & 2.29 (1.13) & \\
\hline \multicolumn{5}{|l|}{$\begin{array}{l}\text { Personal history of } \\
\text { SMl }\end{array}$} \\
\hline Personal history & $2.63(0.73)$ & 0.44 & $2.51(0.85)$ & 0.42 \\
\hline No history & $2.52(0.62)$ & & 2.30 (1.14) & \\
\hline \multicolumn{5}{|l|}{ Relative with SMI } \\
\hline Parent & $2.56(0.67)$ & 0.55 & $2.45(0.71)$ & 0.10 \\
\hline Child & $2.57(0.68)$ & & $2.46(0.82)$ & \\
\hline Sibling & $2.46(0.62)$ & & $2.10(1.51)$ & \\
\hline \multicolumn{5}{|l|}{$\begin{array}{l}\text { Relative's } \\
\text { diagnosis }\end{array}$} \\
\hline Schizophrenia & $2.44(0.62)$ & 0.31 & $2.34(0.79)$ & 0.93 \\
\hline Schizoaffective & $2.64(0.59)$ & & 2.27 (1.99) & \\
\hline Bipolar disorder & $2.53(0.64)$ & & $2.35(0.78)$ & \\
\hline
\end{tabular}

\section{Test-retest reliability}

Strong test-retest reliability over a 1-month period was demonstrated for the 30-item SSRMI as a whole $(r=0.90, P<0.001)$, as well as for the core conceptual content areas individually: status loss and discrimination $(r=0.78, P<0.001)$, separation $(r=0.81$, $P<0.001)$, stereotyping $(r=0.78, P<0.001)$, culpability $(r=0.80$, $P<0.001)$ and devaluation $(r=0.84, P<0.001)$.

\section{Relationships with demographic variables}

Investigation of groups in the data by ANOVA found that the SSRMI scores were unrelated to family member's diagnosis, sex, relationship to family member with mental illness, or presence/ absence of a personal history of SMI (Table 3).

The SSRMI 30-item scale had statistically significant correlations in the expected directions with the CES-D, DCCF, RSE, and ES (Table 4).

\section{Exploratory-factor analysis}

The number of factors to be retained for analysis differed across the various methods applied: The scree plot (supplementary Fig. 1) suggested a one-factor solution (explaining $27.5 \%$ of the variance), Kaisers criterion suggested seven, parallel analysis suggested four factors and Velicer's MAP test suggested five. The results from maximum-likelihood extraction established that the five components accounted for $44.57 \%$ of the total available variance. However, the five components extracted did not align closely with the theoretically derived surface structure of the instrument, and subsequent analyses with two, three and four factors extracted and subject to oblique rotation did not provide any further support for the five subscales. The final exploratory-factor analysis was conducted to investigate the items as having a one-factor structure showed that a single-extracted factor explained $29.57 \%$ of the variance, with 26 of the 30 items having significant loadings on this factor. All five subscales were well represented.

\section{Ten-item scale}

At $T_{1}, 23 \%$ of participants had scores at midpoint or higher on the ten-item SSRMI. Internal reliability of the ten-item short-form SSRMI was very good $(\alpha=0.82)$, and Cronbach's alpha could not be improved by removing any of the items. Test-retest reliability was also good $(r=0.86, P<0.001)$.

Investigation of groups in the data by ANOVA found that the ten-item SSRMI scores were unrelated to sex, relationship to family member with mental illness, family member's diagnosis or presence/absence of a personal history of SMI (Table 3). The tenitem short-form SSRMI had meaningful associations with the CES-D, DCCF, RSE, and ES (Table 4). In sum, the pattern of associations between the 30- and 10-item SSRMI is identical; this confirms the utility of the abbreviated version of the scale.

\section{Discussion}

\section{Main findings}

We developed a novel, comprehensive measure of internalised stigma among first-degree family members of people diagnosed with SMI. Using a mixed-methods approach, we developed a 30item measure with excellent internal reliability, and appropriate test-retest reliability, for which we found evidence in support of construct validity. Contrary to expectations, psychometric analyses did not provide support for five subscales in the instrument. Rather, across analyses it seemed appropriate to infer that the new scale is best understood as tapping a single overarching construct. A pragmatic consequence of this conclusion was the possibility of developing a brief version of the instrument - the ten-item SSRMI retained the broad content coverage of the full instrument and demonstrated comparable psychometric features. As the two versions of the scale are comparable in terms of psychometric features, to ease response burden for participants, the 10-item SSRMI may be preferable to the 30 -item version in many settings.

We note that analyses of Ritscher et al's ISMI generated a similar pattern of findings to those described here, ${ }^{16}$ with exploratory analyses suggesting that self-stigma because of a personal diagnosis (while theoretically referring to a number of psychosocial processes) is best measured in a single construct and as a single-scale score.

Scores above midpoint on the ISMI have been used to define proportions of studied groups of individuals with mental illness as having 'high stigma'. ${ }^{28}$ Our finding that approximately a quarter of participants scored at or above midpoint on the SSRMI is broadly comparable with proportions of individuals with mental illness who score above midpoint on the ISMI. ${ }^{28}$ Although it is not possible to draw direct comparisons between the two sets of data, it does suggest support for the concept that self-stigma is an important issue for family members of people with $\mathrm{SMI},{ }^{3,14,15}$ and that there may be a need for the development of interventions (for example psychoeducation, ${ }^{29}$ genetic counselling ${ }^{30,31}$ ) designed to reduce self-stigma in this population. . $^{3,32,33}$

Table 4 Correlations of the Self-Stigma in Relatives of people with Mental Illness (SSRMI) 30-item and 10-item scales with external correlates

Center for Epidemiology Scale for Depression

Devaluation of Consumer and Consumer Families Scale

Rosenberg Self-Esteem Scale

Empowerment Scale 30-item SSRMI, $r(P)$

$0.38(<0.001)$
$0.44(<0.001)$
$-0.30(<0.001)$
$-0.23(0.018)$
10-item SSRMI, $r(P)$

$0.36(<0.001)$

$0.41(<0.001)$

$-0.28(<0.001)$

$-0.23(0.021)$ 


\section{Limitations}

Some participants in our study also self-reported a personal history of mental illness, which could potentially be seen as a limitation of our study group. We decided against excluding participants with a personal history of mental illness in the interests of ecological validity, and explicitly instructed participants to focus on their experience as a family member. Our approach was supported by the finding that having a personal diagnosis did not relate to SSRMI scores. Further, our data suggest that perhaps self-stigma as a result of a family member's diagnosis could be different from selfstigma related to a personal diagnosis.

We did not assess the utility of the scale among family members other than first-degree biological relatives, its potential applicability for second-degree and non-biological family members remains to be assessed.

\section{Implications}

While other instruments have been used to measure stigma in relatives of people with mental illness, ${ }^{17,18,20,21}$ the SSRMI is the first and only self-stigma measure to be developed with direct input from family members to specifically and comprehensively measure self/internalised stigma among first-degree family members of individuals with mental illness. Robust analyses demonstrate that it has strong psychometric properties. The SSRMI has numerous applications in both clinical and research settings to measure self-stigma and to serve as a useful tool to measure the impact of interventions designed to improve outcomes in relatives of people with mental illness.

E. Morris, MSC, Department of Psychiatry, University of British Columbia, Vancouver, BC Canada; C. Hippman, MSc, Women's Health Research Institute and Department of Psychiatry, University of British Columbia, Vancouver, BC, Canada; G. Murray, PhD, Swinburne University of Technology, Centre for Mental Health, Melbourne, Australia; E.E. Michalak PhD, Department of Psychiatry, University of British Columbia,

Vancouver, BC, Canada; J.E. Boyd, PhD, San Francisco VA Health Care System and University of California, San Francisco, CA, USA; J. Livingston, PhD, Department of Criminology, Saint Mary's University, Halifax, NS, Canada; A. Inglis, MSC, Department of Psychiatry and Department of Medical Genetics, University of British Columbia, Vancouver, BC, Canada; P. Carrion, MSC, Department of Psychiatry, University of British Columbia, Vancouver, BC, Canada; J. Austin, PhD, Department of Psychiatry and Department of Medical Genetics, University of British Columbia, Vancouver, BC, Canada

Correspondence: Jehannine C. Austin, Rm A3-112, University of British Columbia, 938 W 28th Ave, Vancouver, BC, Canada V5Z 4H4. Email: jehannine.austin@ubc.ca

First received 11 Jul 2017, final revision 29 Sep 2017, accepted 12 Oct 2017

\section{Funding}

The development of the scale was made possible by funding from UBC's Hampton Grant program, and J.A. was supported by the Michael Smith Foundation for Health Research, the Canadian Institutes of Health Research, BC Mental Health and Addictions Services, and the Canada Research Chairs program.

\section{Acknowledgements}

The authors would like to thank all participants who participated in each phase of the scale's development, as well as all members of the Translational Psychiatric Genetics Group for their ongoing support.

\section{Supplementary material}

Supplementary material is available online at https://doi.org/10.1192/bjp.2017.23.

\section{References}

1 American Psychiatric Association. Diagnostic and Statistical Manual of Mental Disorders (4th edn), DSM-IV. APA, 1994.
2 Hinshaw SP, Stier A. Stigma as related to mental disorders. Ann Rev Clin Psychol 2008; 4: 367-93.

3 Angermeyer MC, Schulze B, Dietrich S. Courtesy stigma: a focus group study of relatives of schizophrenia patients. Soc Psychiatry Psychiatr Epidemiol 2003; 38: 593-602

4 Corrigan P, Miller FE, Watson A. Blame, shame, and contamination: the impact of mental illness and drug dependence stigma on family members. J Fam Psychol 2006; 20: 239-46.

5 Phelan JC. Genetic bases of mental illness - a cure for stigma? Trends Neurosci 2002; 25: 430-1.

6 Corrigan PW. Target-specific stigma change: a strategy for impacting mental illness stigma. Psychiatr Rehabil J 2004; 28: 113-121.

7 Corrigan PW, Kerr A, Knudsen L. The stigma of mental illness: explanatory models and methods for change. Appl Prevent Psychol 2005; 11: 179-190.

8 Livingston JD, Boyd JE. Correlates and consequences of internalized stigma for people living with mental illness: a systematic review and meta-analysis. Soc Sci Med 2010; 71: 2150-61.

9 Shih M. Positive stigma: Examining resilience and empowerment in overcoming stigma. Ann Am Acad Pol Soc Sci 2004; 591: 175.

10 Boyd Ritsher J, Phelan JC. Internalized stigma predicts erosion of morale among psychiatric outpatients. Psychiatry Res 2004; 129: 257-65.

11 Corrigan PW, Watson AC. The paradox of self-stigma and mental illness. Clin Psychol Sci Pract 2002; 9: 35-53.

12 van der Sanden RLM, Bos AER, Stutterheim SE, Pryor JB, Kok G. Stigma by association among family members of people with a mental illness: a qualitative analysis. J. Comm App/ Soc Psychol 2015; 25: 400-17.

13 van der Sanden RLM, Bos AER, Stutterheim SE, Pryor JB, Kok G. Experiences of stigma by association among family members of people with mental illness. Rehab Psychol 2013; 58: 73-80.

14 Ostman M, Kjellin L. Stigma by association: psychological factors in relatives of people with mental illness. Br J Psychiatry 2002; 181: 494.

15 van der Sanden RLM, Pryor JB, Stutterheim SE, Kok G, Bos A. Stigma by association and family burden among family members of people with mental illness: the mediating role of coping. Soc Psychiatr Psychiatric Epidemiol 2016; 51: 1233.

16 Ritsher JB, Otilingam PG, Grajales M. Internalized stigma of mental illness: psychometric properties of a new measure. Psychiatry Res 2003; 121: 31-49.

17 Mak WWS, Cheung RYM. Affiliate stigma among caregivers of people with intellectual disability or mental illness. J Appl Res Intellect Disabil 2008; 21 : 532-45.

18 Szmukler Gl, Herrman H, Colusa S, Benson A, Bloch S. A controlled trial of a counselling intervention for caregivers of relatives with schizophrenia. SOC Psychiatry Psychiatric Epidemiol 1996; 31: 149-155.

19 Link BG, Phelan JC. Conceptualizing stigma. Ann Rev Sociol 2001; 27: 363-85.

20 Zisman-Ilani Y, Levy-Frank I, Hasson-Ohayon I, Kravetz S, MashiachEizenberg M, Roe D. Measuring the internalized stigma of parents of person with a serious mental illness: the factor structure of the parents' internalized stigma of mental illness scale. J Nerv Ment Dis 2013; 210: 183-7.

21 Struening EL, Perlick DA, Link BG, Hellman F, Herman DSW, Sirey JA. The extent to which caregivers believe most people devalue consumers and their families. Psych Serv 2001; 52: 1633-8.

22 National Institute of Mental Health Genetics Initiative. Family Interview for Genetic Studies (FIGS). National Institute of Mental Health, 1992.

23 Kass RA, Tinsely HEA. Factor analysis. J Leisure Res 1979; 11: 120-38.

24 Radloff LS. The CES-D scale: a self-report scale for research in the general population. Appl Psychol Meas 1977; 1: 385-401.

25 Rosenberg M. Society and the Adolescent Self-Image. Princeton University Press, 1965.

26 Rogers ES, Chamberlin J, Ellison ML, Crean TA. A consumer-constructed scale to measure empowerment among users of mental health services. Psychiatr Serv 1997; 48: 1042-7.

27 Buuren S. Multiple imputation of discrete and continuous data by fully conditional specification. Stat Methods Med Res 2007; 16: 219-42.

28 Boyd J, Adler EP, Otilingam PG, Peters T. Internalized stigma of mental illness (ISMI) scale: a multinational review. Comp Psychiatry 2014; 55: 221-31.

29 Levy-Frank I, Hasson-Ohayon I, Kravetz S, Roe D. Family psychoeducation and therapeutic alliance focused interventions for parents of a daughter or son with severe mental illness. Psychiatry Res 2011; 189: 173-9.

30 Austin J, Honer W. Psychiatric genetic counselling for parents of individuals affected with psychotic disorders: a pilot study. Early Int Psychiatry 2008; 2: 80-89.

31 Inglis A, Koehn D, McGillivray B, Stewart E, Austin J. Evaluating the first spe cialist clinical psychiatric genetic counseling service: uptake and impact. Clin Genet 2015; 87: 218-224. 
32 Zauszniewski JA, Bekhet AK, Suresky MJ. Factors associated with perceived burden, resourcefulness, and quality of life in female family members of adults with serious mental illness. J Am Psychiatric Nurs AssOC 2008; 14 125-135.
33 Buizza C, Schulze B, Bertocchi E, Rossi G, Ghilardi A, Pioli R. The stigma of schizophrenia from patients' and relatives' view: a pilot study in an Italian rehabilitation residential care unit. Clin Pract Epidemiol Ment Health 2007; 3: 23.

\section{psychiatry in literature}

\section{Struwwelpeter by Heinrich Hoffmann}

\section{Jonathan Davidson}

The psychiatrist Heinrich Hoffmann received his medical training in Halle, Heidelberg and Paris. In 1851, he founded the Frankfurt mental hospital, where he lived and worked as superintendent until retiring in 1888. Hoffmann was an innovator, who improved conditions of patients, and introduced enlightened views on the nature of mental illness; he authored a textbook on mental illness and epilepsy, and has been referred to as 'the first representative of child and adolescent psychiatry'. His name is perpetuated in the form of the biennial Hoffmann Medal of the World Federation of attention-deficit hyperactivity disorder (ADHD), awarded for distinguished work in the field of ADHD. History knows him better as the author of a children's book, 'Der Struwwelpeter oder Lustiger Geschicten und Drollinger Bilder für Kinder von 3-6 Jahren' ('Tousle-headed Peter: Cheerful Stories and Funny Pictures for Children from 3-6 Years').

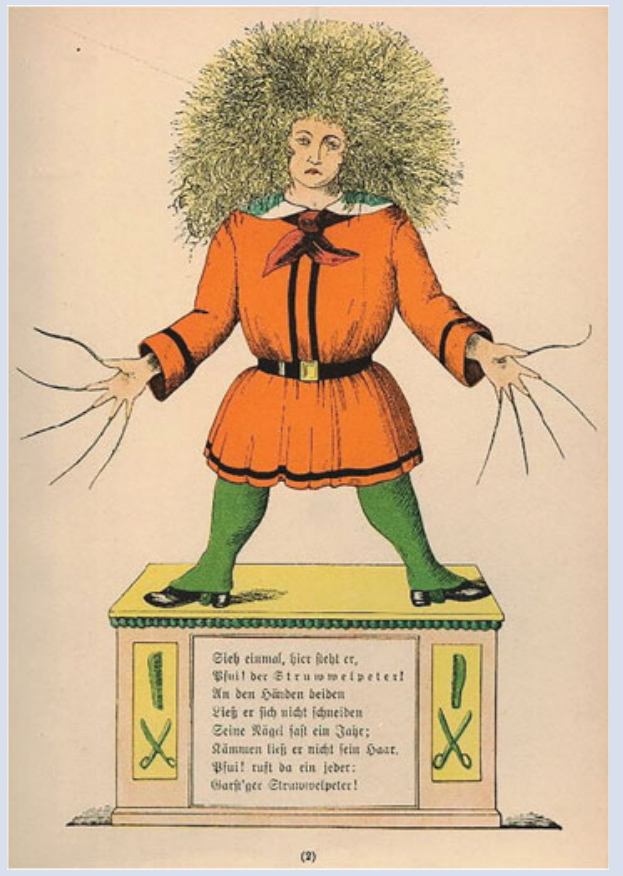

Fig. 1 Heinrich Hoffmann: Der Struwwelpeter; Frankfurt am Main: Literarische Anstalt Rütten \& Loening, 1917.

Image out of copyright. https://en.wikpedia.org/wiki/Struwwelpeter\#/media/File:H_Hoffmann_Struwwel_03.jpg. Accessed 09-22-2017.

Hoffmann wrote Struwwelpeter in 1845 as a Christmas comic book for his three-year old son, with no intention of publication. Hoffmann later changed his mind, and Struwwelpeter has since been translated into most European languages, one English translation having been made by Mark Twain. Sales of the book continue today - by 1917, there were 400 editions and today this number is far in excess of that; its enduring success would perhaps have astonished Hoffmann. The book has inspired a host of music, film, TV and stage adaptations or literary mentions throughout the 20th century. Three examples include a poem 'The Witnesses' by W.H. Auden, which refers to the scissor man, Agatha Christie in 'Curtain' and a post-punk band, 'Shock Headed Peters', named after the book's main character.

Strumwelpeter is considered to be the precursor of comic books. It contains ten cautionary illustrated tales written in verse, all intended to make children realize the dreadful consequences of misbehavior. From the viewpoint of psychiatry, it is noteworthy that many of the stories describe children with psychiatric conditions now recognized in contemporary diagnostic manuals. The tale of Fidgety Phil offers a classic description of attention-deficit hyperactivity - not only its symptoms but the family conflicts that it can arouse. Johnny Head in Air can be interpreted as a representation of ADHD or petit mal absence. Children with an eating disorder that proved to be fatal (Augustus and the soup), pyromania (Harriet and the matches) and cruel antisocial behavior (The Story of Cruel Frederick) are included, along with stories depicting dissocial racist behavior and thumb sucking.

Even though Struwwelpeter is no longer customary childhood reading, it continues to exert an influence in today's culture and represents a remarkably insightful early Victorian portrayal of childhood psychopathology, identifying syndromes that now appear in the diagnostic manuals. 